\title{
Um combate em dois fronts ${ }^{*}$
}

\author{
Raul Amaro de Oliveira Lanari ${ }^{* *}$
}

Choay, Françoise. O patrimônio em questão: antologia para um combate. Belo Horizonte: Fino Traço, 2011.

Lançado no Brasil no ano de 2011, o livro O patrimônio em questäo: antologia para um combate, da pesquisadora francesa Françoise Choay, integra um campo de investigação já consolidado nas áreas da história, antropologia e arquitetura/urbanismo: o patrimônio cultural. Autora de $A$ alegoria do patrimônio (1992), Choay possui uma visão crítica do processo de expansão da "cultura do patrimônio" nos tempos da cultura de massas, o que pode ser percebido pelo título de seu novo livro. Seu combate pode ser resumido como a luta contra o esvaziamento da função memorial dos monumentos no contexto urbano e, assim, trata-se de uma discussão que interessa aos estudiosos da história das cidades, bem como da história das políticas públicas na área da cultura.

Choay não se encontra sozinha neste combate. A "questão urbana" é objeto de estudo de uma série de estudiosos franceses, desde Henri Lefebvre (1920-1991), autor de $O$ direito à cidade (1968), até Henri- Pierre Jeudy, autor de Espelho das cidades (2005). Da publicação do célebre livro de Choay em 1992 aos dias atuais observaram-se diversos esforços para o aprofundamento das temáticas abordadas pela autora. No caso brasileiro, é necessário citar os estudos de José Reginaldo Santos Gonçalves, Antônio Gilberto Ramos Nogueira, Ulpiano Bezerra Toledo de Meneses, Márcia Regina Chuva, Silvana Rubino, Maria Cecília Londres Fonseca, Rogério Proença Leite e Myriam Sepúlveda dos Santos. Percebe-se, portanto, que a contribuição atual de Choay encontra ampla receptividade na comunidade acadêmica brasileira e mundial.

Seria de se esperar, dada a importância da autora no debate sobre o patrimônio e as cidades, que seu novo livro trouxesse novidades analíticas, pontos de aprofundamento de suas hipóteses. Não é isso o que se percebe após a leitura do mesmo. O patrimônio em questão: antologia para um combate sintetiza ideias já consagradas, possui generalizaçóes, por vezes apresenta uma visão esquemática do processo histórico que procura identificar. O livro é dividido em três partes: um Prefácio, uma Introdução e uma Antologia de Textos. Dedicaremos as próximas páginas à análise dessas seçóes.

A autora inicia a obra com um pequeno prefácio, no qual explica as condiçóes de sua elaboração - disciplinas ministradas na universidade para futuros arquitetos e urbanistas e cursos destinados a profissionais interessados pela história ou gestáo do patrimônio. Apresenta seu combate contra as confusões terminológicas que apagaram 
a profundidade da preservação do patrimônio, retirando dele a função de evocar a memória viva, e propóe uma tomada de consciência. Trata-se de um livro destinado a um público duplo, formado por acadêmicos e pesquisadores, mas também pelo "público não especializado e não informado dos cidadãos" (p. 10). Para atingir seu fim, Choay admite que realizou algumas generalizaçōes para condensar conteúdos já explorados em $A$ alegoria do patrimônio. Percebe-se então que o caráter generalizante e por vezes pouco denso da exposição decorre de uma escolha de Choay, que sinaliza uma tentativa de alargamento do debate público sobre o patrimônio e as cidades. Talvez a inovação maior da obra, portanto, seja seu caráter de um "combate bifronte" e não o aprofundamento da reflexão teórica.

A introdução do livro parte da análise genealógica do conceito de patrimônio. Choay recupera inicialmente a distinção entre monumentos e monumentos históricos, raízes lexicais do conceito difundido mundialmente nos dias atuais. Os primeiros são construídos com clara intenção de evocar a lembrança e ligam-se à memória viva. Já os segundos são elaboraçôes de determinado saber sobre a realidade, escolhas efetuadas entre um vasto conjunto de monumentos de acordo com os valores históricos, artísticos, políticos, dentre outros. Para Choay, os monumentos têm longa existência, com presença marcante nas sociedades humanas desde tempos muito remotos, enquanto os monumentos históricos são característicos da sociedade europeia pelo menos desde a Alta Idade Média. A despeito da impor- tância dada a ambos, a autora ressalta que a ação destruidora esteve presente e foi até predominante na maioria dos períodos históricos, principalmente no continente europeu. Sacudida por revoluçóes culturais, a Europa gestou o culto moderno dos monumentos, a partir da Renascença e da Revoluçáo Industrial, em diferentes graus de amplitude, de acordo com as regiôes.

A autora argumenta que a evolução do monumento ao monumento histórico ocorreu de forma lenta entre os séculos XV e XIX e mais rapidamente na virada do século XIX para o XX, com consequências importantes. Três revoluçóes culturais europeias teriam impulsionado estas mudanças. A primeira, na Renascença, caracterizou-se pelo afrouxamento do teocentrismo medieval. $\mathrm{O}$ ser humano deixou de ser considerado mera criatura e a ele passou a ser atribuída uma capacidade criadora, o que levou ao interesse nas manifestaçôes da atividade humana em diferentes épocas. Novos tipos profissionais urbanos como o arquiteto e o artista plástico se destacaram por desempenharem atividades relacionadas ao apuro técnico, ao deleite estético e à história dos homens. Arte e técnica andavam juntas e garantiam a legitimidade de um novo saber, histórico. As obras da Antiguidade, em muitos casos utilizadas como fontes para a confirmação ou negaçáo dos textos antigos, foram as primeiras a receber a atençáo desses novos homens de artes e saberes - os eruditos antiquários. As cidades italianas foram precursoras dessa primeira revoluçáo cultural no século XV, que se estendeu aos reinos vizinhos a partir do século seguinte. Segundo a autora, "os anti- 
quários e suas Antiguidades" caracterizaram uma nova forma de se relacionar com o passado humano por intermédio do ambiente construído (p. 16-17).

O desenvolvimento desse culto às Antiguidades pela ação dos antiquários seguiu uma linha evolutiva irregular até o começo do século XIX. Porém, o saber erudito desses novos homens de letras foi responsável por uma "tomada de consciência da unidade europeia" (p. 18). Três teriam sido os momentos dessa evolução. Até o século XVII predominou a ação dos antiquários na catalogação dos monumentos e na defesa de métodos para sua reconstrução e inserçáa nas cidades antigas. No século XVIII os estudos passaram a apresentar vasta documentação iconográfica. Entretanto, esse saber mais livresco, calcado na leitura dos textos clássicos e que já se fazia presente no período anterior, não logrou preservar as Antiguidades. No final do século XVIII e no início do XIX, as mutaçóes nos saberes existentes, com a ascensão das ciências naturais, as obras dos antiquários, historiadores da arte ou antropólogos se tornaram mais pretensamente científicas, o que influenciou a valorização da relação entre texto e imagem.

Entre fins do século XIX e início do XX, a segunda revolução cultural europeia, a Revolução Industrial, introduziu o maquinismo na cultura ocidental, com o paulatino predomínio da técnica e da ciência. Foi essa a época do surgimento dos monumentos históricos, amparado por políticas oficiais de proteção que desenvolveram procedimentos diversos de conservação e restauro. Como no Renascimento, essa segunda revolução teve grandes impactos nas relaçôes sociais, divididos, pela autora, em quatro grupos: 1. os campos do saber, com a ascensão da história e sua unificação em torno de diversas subdisciplinas; 2 . a sensibilidade estética, com o romantismo e atribuição de uma importância praticamente transcendente, religiosa à obra de arte; 3. a revoluçáo das técnicas, com a fotografia, a imprensa e os estudos físico-químicos; 4. o êxodo rural, a desordem dos modos de vida tradicionais e, principalmente, a inauguração de uma nova relação com o tempo. A velocidade da sociedade da máquina levou a mudanças bruscas nas cidades, o que deu margem a uma nova nostalgia característica do século XIX, o século da história. Essa nostalgia arrebatou as elites nacionais mais abastadas (p. 21-22).

O desenvolvimento desse sentimento nostálgico também teve forte impulso dos nacionalismos que vicejaram na Europa no último quartel do século XIX até pelo menos o final da Segunda Guerra Mundial. O leque espacial e temporal dos monumentos - agora históricos e nacionais - foi ampliado e ultrapassou as construçóes da Antiguidade e do Medievo para adentrar no ambiente construído pré-industrial. A prática preservacionista chegou a alguns países da Ásia e das Américas, como o Brasil, onde as primeiras políticas de preservaçáo do patrimônio foram implementadas na década de 1930. Foram elaborados complexos aparatos teóricos e jurídicos para a proteção dos monumentos e a aferiçáo de seus valores. Algumas diferenças eram marcantes e caracterizaram escolas de pensamento que influenciam até hoje os pontos de vista na- 
cionais sobre as políticas de preservação. Enquanto na França houve ênfase maior na construção de categorias jurídicas por parte do Estado, dentre as quais a do "tombamento" foi a mais importante, nos países de língua inglesa a preservação ficou a cargo de associaçóes particulares de estudiosos e colecionadores. $\mathrm{O}$ modelo francês previa uma reconstituição dos edifícios significativos e isolados em um estado de completude ideal. $\mathrm{O}$ modelo inglês afastava-se dessas proposiçóes, valorizando a ruína e conferindo a ela um caráter quase sagrado. A escola italiana, por sua vez, pensou as técnicas de restauro e ensaiou uma proposta de reutilização dos edifícios antigos. A tradição alemã, da qual fez parte Alöis Riegl, foi a primeira responsável por uma análise fundada nos valores contraditórios dos quais todo monumento é portador (p. 22-26).

$\mathrm{O}$ último ciclo de mudanças que teria contribuído para a atual valoração do patrimônio é situado após a Segunda Guerra Mundial, no contexto de internacionalização da cultura ocidental e da organização dos organismos multilaterais, como a ONU, a Unesco, a OMC e outros. Introduziu também as inovaçôes tecnológicas da computação e dos ambientes virtuais, das próteses urbanas enxertadas a partir de concepçóes de cultura globalizantes. Essa terceira revolução cultural não foi apenas europeia, se caracterizou por seu aspecto mundial. Foi o período no qual surgiu a noção de "Patrimônio Cultural da Humanidade”, responsável por uma profunda modificação na relação da sociedade com seus monumentos, históricos ou não. A existência de uma suposta cul- tura mundial, apoiada pelos grandes grupos de comunicaçóes e pelas estratégias de marketing cultural, trouxe em seu bojo a planificação dessa mesma cultura, a perda de suas especificidades e dos valores que definiram a existência dos monumentos e monumentos históricos em sua evolução no tempo. A autora constata que as diferenças entre estes dois últimos são cada vez mais apagadas por essa nova concepção globalizante de cultura, e que ambos se mostram cada vez mais esvaziados de valor simbólico e participantes de ações de estilização urbana. Os edifícios e os processos de restauro, por sua vez, são cada vez mais frutos dos softwares, e o arquiteto limitou sua atividade à boa operação desses programas.

A autora não ignora a mercantilização desse patrimônio, que serve bem a estratégias políticas e empresariais de "responsabilidade social". Tratado como um produto cultural, o patrimônio passa a ser um pastiche, ou uma casca sem conteúdo (p. 34-38). O esvaziamento simbólico do patrimônio foi acompanhado por um boom de consumo dos bens culturais. Cultura passou a ser sinônimo de entretenimento, e as políticas de preservação se aproximaram das de turismo, muitas vezes confundidas com elas. Assistiu-se a um processo de reconstrução de monumentos com a retirada das populaçóes originais e a adequação a padróes cada vez mais homogêneos de visitação por pessoas de alto poder aquisitivo. Choay termina sua Introdução com duras críticas ao panorama descrito, e conclama não somente os estudiosos, mas sobretudo os cidadãos, à tomada de consciência do apagamento daquilo que 
caracteriza a vida humana no espaço, a diferença e a ação do próprio homem. Ela refuta as soluçóes padronizadas em assuntos de preservação do patrimônio edificado e recupera exemplos franceses, italianos e colombianos para mostrar que ainda é possível revitalizar sítios ouvindo a comunidade e pensando estratégias inusitadas para vencer o formalismo reinante na prática patrimonial. Ao mesmo tempo, exalta o Homo sapiens sapiens em detrimento do Homo protheticus, artificial, mecanizado e estanque.

A segunda parte do livro é constituída por 21 seleçôes de textos significativos para ilustrar a evolução apresentada pela autora em sua introdução. Os textos são precedidos de comentários explicativos, nos quais a obra do autor é contextualizada no tempo e no espaço em que foi produzida. Os autores selecionados são: Abade Suger, Poggio Bracciolini, Pio II Piccolomini, Baldassare Castiglione, Raffaello Sanzio, Leão X, Jacob Spon, Bernard de Montfaucon, Aubin-Louis Millin, Félix de Vicq D’azyr, Quatremère de Quincy, Victor Hugo, John Ruskin, Eugène Violet-Le-Duc, Karl Marx, Alöis Riegl, Gustavo Giovanoni, André Malraux, além de excertos da Carta de Atenas (1931), da Carta de Veneza (1964) e do documento resultante da Convenção pela Proteção do Patrimônio Mundial, organizada pela Unesco em 1975. Os textos são provenientes, em sua totalidade, da Europa, e a autora justifica a escolha pelo fato de se tratar de uma obra nascida dentro das salas de aula europeias, por mais que a problemática seja mundial. $\mathrm{Na}$ maioria dos textos as seleçóes privilegiam pontos considerados positivos. Os co- mentários críticos da autora se aprofundam na medida em que os textos vão se tornando contemporâneos. Dentre todos, os mais incisivos são os destinados às proposiçóes de André Malraux, primeiro-ministro da Cultura francês e principal defensor da noçáo de "patrimônio cultural", e às propostas da Convenção para a Proteçáo do Patrimônio Mundial, de 1975.

Choay explica que prefere combater por algo a combater contra algo. Seu combate é pela capacidade criadora, pela defesa da humanidade fundada na diferença, pela desmercantilização do patrimônio e a reapropriação dos bens imóveis legados pelo passado a partir de usos contemporâneos. Ela advoga a participaçáo das comunidades locais, associaçóes civis de moradores, em substituição ao modelo estatista de preservação dos monumentos, argumentando que somente os primeiros podem buscar soluções não artificiais, enraizadas espacial e temporalmente.

O historiador dedicado a trabalhos técnicos ou acadêmicos na área do patrimônio pode terminar o livro se perguntando sobre a ausência do patrimônio imaterial nas análises de Françoise Choay, o que não seria desmedido. Pelo menos desde o início do século XXI, uma noção mais antropológica passou a ser considerada, ainda que sua aplicabilidade seja restrita em diversos países, sendo o Brasil um desses exemplos. Porém, como já frisado no início do texto, as diferenças entre os olhares de historiadores e arquitetos são partes constitutivas do campo de pesquisa e trabalho aqui abordado. As provocaçóes aguerridas de Françoise Choay em $O$ patri- 
mônio em questão: antologia para um combate fornecem armas poderosas a uma crítica consistente do processo de intervenção arbitrária ocorrido nas grandes cidades, inclusive as brasileiras, supostas "revitalizaçóes" de espaços que na verdade não passam de uma mercantilização do patrimônio, uma estilização cultural urbana com a finalidade de entreter. Isso não seria aplicável também à proteçâo do patrimônio imaterial? Não padecemos hoje de um fascínio pelo retro, pelo vintage esvaziado de valor memorial e cheio de valor de troca? A cultura não vem sendo constantemente tratada por governos como mera organização de eventos? Nesse sentido, o livro de Françoise Choay é muito enriquecedor e pertinente. Ele cumpre com o propósito de atender a dois públicos distintos, de especialistas e leigos, incentivando ambos a pensar além da obra.

* Esta resenha foi produzida como atividade da disciplina "Produção e circulação do conhecimento histórico nos periódicos científicos", ministrada pela professora Regina Horta Duarte no Programa de Pós-Graduaçáo em História da UFMG durante o primeiro semestre de 2013. Agradeço à professora e aos colegas pelas discussóes que deram origem ao texto final.

${ }^{* *}$ Doutorando em história pela Universidade Federal de Minas Gerais, professor de história do Centro Universitário de Belo Horizonte. Belo Horizonte, MG, Brasil. E-mail: ralanari@gmail.com. 